\title{
On the Pragmatic Approach to Counterpossibles
}

\author{
Maciej Sendłak ${ }^{1}$ (i)
}

Received: 5 December 2017 / Revised: 6 February 2018 / Accepted: 3 May 2018 /

Published online: 15 May 2018

(C) The Author(s) 2018

\begin{abstract}
Nina Emery and Christopher Hill proposed a pragmatic approach toward the debate about counterpossibles-i.e., counterfactuals with impossible antecedents. The core of this approach is to move the burden of the problem from the notion of truth value into the notion of assertion. This is meant to explain our pretheoretical intuitions about counterpossibles while claiming that each and every counterpossible is vacuously true. The aim of this paper is to indicate a problematic aspect of this view.
\end{abstract}

Keywords Counterpossibles · Counterfactuals · Pragmatics · Assertion · Possible worlds · Impossible Worlds

The subject of this paper is counterpossibles; i.e., subjunctive conditionals of the form 'If it were the case that $A$, then it would be the case that $C$ ' ('A>C'), where ' $A$ ' expresses impossibility (necessary falseness). ${ }^{1}$ The problem of counterpossibles is the problem that arises in the face of worlds semantics for counterfactuals, combined with the assumption that there are no impossible worlds. The consequence of these is that every counterfactual with an impossible antecedent is vacuously true. This, however, is difficult to square with pre-theoretical intuitions that some counterpossibles are false. Consequently, there is a question of whether it is justified to introduce a modification of

\footnotetext{
${ }^{1}$ Earlier versions of this material were presented in Szczecin (University of Szczecin) at the seminar of "Cognition \& Communication Research Group" and in Munich (Ludwig Maximilian University of Munich) at "The ninth European Congress of Analytic Philosophy." I am grateful to the participants of these meetings for their helpful comments and discussions, especially to Arkadiusz Chrudzimski and Joanna OdrowążSypniewska. I would also like to thank the anonymous reviewers for this journal for their comments concerning the earlier versions of the paper. This material is based on the work supported by National Science Centre (NCN), Poland (Grant No.2016/20/S/HS1/00125).
}

Maciej Sendłak

maciej.sendlak@gmail.com

1 Institute of Philosophy, University of Warsaw, Krakowskie Przedmieście 3, 00-927 Warszawa, Poland 
the standard approach towards counterfactuals and extend it by introducing the notion of impossible worlds.

The advocates of what Timothy Williamson called the 'orthodox view,' and what was developed in the classic works of Robert Stalnaker (1968) and David Lewis (1973), give a negative answer to this question and argue that despite pre-theoretical intuitions, every counterpossible is vacuously true (Williamson 2016). The unorthodox opposition argues in favor of a modified account, according to which some counterpossibles are true and others are false. The modification centers around extending the standard approach by introducing impossible worlds (Yagisawa 1988; Nolan 1997; Priest 2009; Berto 2013; Brogaard and Salerno 2013; Kment 2015; Sendłak 2017).

Considering the motivation for the belief in non-vacuously true (or false) counterpossibles, advocates of the orthodox view are trying to explain these intuitions away by suggesting that they only give us evidence about pragmatics, not semantics. Consequently, there is supposed to be no need to change the standard approach towards truth-values of counterfactuals. Few of them, however, developed this claim in detail. A notable exception to this is the approach proposed by Emery and Hill (2017). The aim of this paper is to argue in favor of the claim that, while pragmatic aspects of counterpossibles are of great importance for the debate, Emery and Hill's proposal is affected by the problem of tu quoque, which allows one to doubt its plausibility. The exposition of this problem will help to indicate a close bond between counterpossibles and counterfactuals with merely possible antecedents. I believe that this bond, along with the assumption that some counterfactuals are false, supports the unorthodox view. Before we go any further, however, we will start with an outline of the reasons why the orthodox view is considered to be an inadequate account of counterpossibles.

\section{The problem of counterpossibles}

The starting point of the debate between the orthodox and unorthodox views is the observation that the former might be considered insufficient when it comes to a proper account of counterfactuals in general. This is so because-contrary to the thesis of orthodoxy - it seems to us that we can indicate non-vacuously true or false counterpossibles. Popular examples of such sentences are:

(1) If Kate drew a squared circle, mathematicians would be impressed.

(2) If Kate drew a squared circle, mathematicians would not be impressed.

(3) If intuitionist logic were the correct logic, then the law of the excluded middle would not be unrestrictedly valid.

(4) If intuitionist logic were the correct logic, then the law of the excluded middle would be unrestrictedly valid.

(5) If whales were fish, they would have gills.

(6) If whales were fish, they would not have gills.

(7) If Albert Einstein were a married bachelor, he would be a man.

(8) If Albert Einstein were a married bachelor, he would not be a man. 
Each of the above contains impossible antecedents, which, according to the orthodox approach, makes all of these counterfactuals vacuously true. ${ }^{2}$ Thisadvocates of the unorthodoxy argue - seems to be in conflict with the fact that we would prefer to consider only some of them to be true and others to be false. Since, according to intuitionistic logic, the law of the excluded middle is not unrestrictedly valid, we tend to believe in the truth of (3) and falseness of (4). Also, it seems that if Kate were to draw a squared circle, it would be a highly impressive achievement. After all, she would have succeeded in doing something mathematically impossible. Similarly, since fish have gills, if whales were fish they would have gills as well. Finally, every bachelor is a man, so if Einstein were a married bachelor, he would be a man.

Even though we have assumed that an advocate of unorthodoxy would consider (1), (3), (5), and (7) to be true, we did so merely for heuristic reasons. While it is relatively easy to think about contexts in which these are true and (2), (4), (6), and (8) are false, one may imagine contexts where it is the opposite. As such, one may argue that, contrary to what we have suggested, sentence (2) is true and (1) is false. This might be so, due to the reasoning that if someone drew a squared circle then it ought to be possible to achieve. As such, mathematicians would not be surprised by this achievement. Similarly, since no man is a married bachelor, if Einstein were a married bachelor, he would not be a man. Surely, there are enough contexts to make any of these counterpossibles true. What is important is that regardless of which of the above is asserted as true ((1) or (2)), the other-advocates of the unorthodoxy claim suggest-should be considered false.

This is by no means a feature exclusive to counterpossibles; it applies to counterfactuals in general. After all, the truth of a given counterfactual often depends on the context of conversation. ${ }^{3}$ Nevertheless, it is assumed that counterfactuals with the same possible antecedent but opposite consequences cannot be simultaneously true. This found expression in an axiom (a4) in Robert Stalnaker's account: $\diamond \mathrm{A} \rightarrow((\mathrm{A}>\mathrm{C}) \rightarrow \sim(\mathrm{A}>\sim \mathrm{C}))(1968,106)$. What advocates of unorthodoxy argue for is that something similar applies to counterpossibles as well, though without the assumption of an antecedent being possible. In other words, what makes a counterpossible non-vacuously true is that a conditional with the same antecedent but opposite consequent is false.

\footnotetext{
${ }^{2}$ What makes these antecedents impossible is that - assuming the validity of the classical logic - there is no logically or metaphysically possible world where any of the mentioned antecedents are true.

${ }^{3}$ An example of this may be found in Quine $(1960,221)$ :
}

(a) If Caesar had been in command [in the Korean War], he would have used the atom bomb.

(b) If Caesar had been in command, he would have used catapults.

We can easily imagine a conversation in which (a) is asserted by a speaker as true, as well as one in which (b) is asserted as such. It is more difficult, however, to imagine a conversation in which both of these are asserted by the same speaker (especially if one assumes that the use of an atomic bomb somehow excludes the use of catapults). 
Because of this, it is believed that the modal status of the antecedent should not affect the relation between the truth values of a pair of counterfactuals with the same antecedent and opposite consequences. ${ }^{4}$

In light of the above, advocates of the unorthodox view argue that the orthodox approach does not address the need for differentiation between the truth values of counterpossibles. As such, this approach is considered to be an insufficient account of counterfactuals in general. ${ }^{5}$ Consequently, it is claimed that one should lean toward the alternative, unorthodox view.

\section{Counterpossibles and assertion}

What seems to be a common orthodox attitude toward the problem of the truth values of counterpossibles is a belief that this is merely a pseudo-problem and that one should not put too much stress on it. In particular, one should not change the original account, which asserts that every counterpossible is true. This is mostly because advocates of the orthodox view indicate that one can explain away an apparent non-vacuous truth value of a counterpossible by pointing out that it is merely a conversational aspect (Lewis 1973). As such, we are not required to believe in the non-vacuous truth value of some counterpossibles:

We have plenty of cases in which we do not want to assert counterfactuals with impossible antecedents, but so far as I know we do not want to assert their negations either. Therefore they do not have to be made false by a correct account of truth conditions; they can be truths which (for good conversational reasons) it would always be pointless to assert. (Lewis 1973, 25)

It seems that for many years this was the main reason why theoreticians of counterfactuals neglected the problem of counterpossibles. They did so by deeming this problem to be a subject for pragmatics rather than for semantics. As such, they claimed that there is no need to reject the orthodox view in favour of the unorthodox. After all, both are focused on the semantics of counterfactuals. This attitude seems to be an exemplification of what Robyn Carston $(2017,453)$ characterizes as 'a time when pragmatics was viewed as the "wastebasket" of linguistics, a bin for dumping whatever recalcitrant bits of utterance meaning could not be accommodated by the formal methods of syntax and semantics.' Nevertheless, because of the increase of interest in the problem of counterpossibles, the question of how the orthodox view could handle

\footnotetext{
${ }^{4}$ It should be mentioned that the formulation of such a general principal is not as easy as it might seem to be. This is due to the following counterexample:

(a) $(\mathrm{A} \wedge \sim \mathrm{A})>\mathrm{A}$;

(b) $(\mathrm{A} \wedge \sim \mathrm{A})>\sim \mathrm{A}$.

Even though (a) and (b) have the same antecedent and opposite consequences, both of them are true (Williamson 2016, 8). Nevertheless, it seems that it is possible to overcome this problem (Sendłak Forthcoming).

${ }^{5}$ This by no means should be taken to be a charge of inconsistency against the orthodox view. For a detailed exposition of the orthodox view, see Williamson (2016).
} 
pre-theoretical intuitions about counterpossibles gained some attention. Moreover, advocates of such an approach indicate a pragmatic solution to this problem, to which we will return shortly.

Obviously, it is not easy to analyze the problem of counterpossibles (and counterfactuals in general) without considering their pragmatics. However, there are reasons to believe that reducing a problem that many believe to be a matter of semantics to pragmatics is an insufficient solution. After all, regardless of the variety of approaches taken toward the distinction between semantics and pragmatics, most (if not all) agree that while pragmatics deal with the usage of a language (or those aspects of language that are context-dependent), the subject of semantics is the meaning and truth conditions of expressions (Szabó 2008). As indicated at the very beginning, the problem of counterpossibles is a problem of truth value, which makes it a semantic issue.

However, in their paper, Emery and Hill (2017) outlined an alternative explanation to the problem of counterpossibles, which might be labelled a pragmatic approach. Their central aim is to provide analysis that, on the one hand, takes into consideration our pre-theoretical intuition about the non-vacuous truth value of counterpossibles and, on the other hand, explains these away without introducing changes to the orthodox approach towards counterfactuals, i.e. without introducing impossible worlds. If the pragmatic approach truly succeeds in doing so, there would be no reason to lean towards the unorthodox view. After all, in such a case, one could deal with the problem of counterpossibles in a way that does not involve either rejecting standard semantics of counterfactuals or introducing impossible worlds.

Emery and Hill argue that there are two main cases for the use of counterpossibles. The first is when we wrongly assume the modal status of an antecedent. The second is when we realize that the antecedent is impossible. It seems that (5) and (6) might be good examples of the first of these two cases. Someone who is not familiar with analyses of the problem of natural kind terms (Kripke 1972; Putnam 1973) may not be aware that it is metaphysically impossible for a whale to be a fish, just as it is impossible for a man to become a bug (as took place in Franz Kafka's novel Metamorphosis). Lacking this knowledge, some people (wrongly) consider the antecedents of (5) and (6) to be possible and not impossible. By virtue of this misunderstandingEmery and Hill claim - they expect (5) and (6) to have different truth values.

Obviously, since these expectations are based on misunderstandings, there is no reason to satisfy them by changing the semantics of counterfactuals. This kind of situation has been characterized by Emery and Hill $(2017,137)$ as one in which 'philosophically unsophisticated people' expect statements that are vacuously true to be non-vacuously true ((1), (3), (5), (7)), and statements which are in fact vacuously true to be non-vacuously false $((2),(4),(6),(8)){ }^{6}$

Even if one shares the observation about intuitions expressed by 'philosophically unsophisticated people,' this surely does not exhaust the circumstances that give us motivation for a belief in non-vacuous counterpossibles. After all, even philosophically sophisticated people may argue in favor of the non-vacuous truth of (5) and the falseness of (6). Moreover, there are also examples of counterfactuals with bluntly impossible antecedents such as (1) and (2), in which philosophical sophistication does

\footnotetext{
${ }^{6}$ The examples used by Emery and Hill differ from those that we refer to. This change should not affect the line of argumentation.
} 
not have a role to play. These are cases in which we do realize that the antecedent of a counterfactual is impossible, and these types of examples seem to be the main reason for modifying the standard analysis of counterpossibles.

However, as Emery and Hill argue, even in such cases one does not need to reject the orthodox view. This assumes shifting the burden of the problem from the question of truth value to the question of assertion. Following this line of thought, we may say that one tends to assert (1), (3), (5), and (7) rather than to assert (2), (4), (6), and (8). The assertion may be motivated by various reasons, one of them being that by asserting (1) we may indirectly express an interesting and true proposition; that is, (1*) 'It is mathematically impossible to round the square.' Similar indirect propositions may be expressed by an assertion of (3), (5), and (7). In the case of (3), it may be the fact that $\left(3^{*}\right)$ 'According to intuitionistic logic there are some truth value gaps.' In the case of (5), it may be the proposition that $\left(5^{*}\right)$ 'Fish have gills.' Finally, in Einstein's case it is proposition $\left(7^{*}\right)$ 'Every bachelor is a man.' In other words, we do assert sentences such as (1), (3), (5), and (7) not because these counterfactuals are non-vacuously true, but because their assertion helps us to indirectly express substantive and true claims. Nevertheless, these assertions should not lead us to the conclusion that counterpossibles (1)-(8) have different truth value. After all — as Emery and Hill pointed out - '[t]here are lots of substantive and true propositions that are never asserted, because speakers regard them as uninteresting' (2017, 138). It seems that (2), (4), (6), and (8) are assumed to be uninteresting, though true, propositions. Moreover, a similar phenomenon takes place when counterpossibles are asserted by philosophically sophisticated and unsophisticated people. As such, both can assert (5) and (7) in order to communicate claims $\left(5^{*}\right)$ and $(7 *)$, respectively.

There is, however, a difference in the explanation of this fact. When it comes to the philosophically sophisticated speaker and audience, the whole process is grounded in a reference to the well-known views of Paul Grice (1975) on conversation's maxims and implicatures. Among the maxims that are supposed to govern conversations, the Maxim of Quantity advises you to make your contribution as informative as is required for the current purposes of the exchange. Assuming that a philosophically sophisticated speaker and his or her audience obey this maxim, the procedure of assertion (5) in order to communicate $\left(5^{*}\right)$ is explained as follows:

For if a speaker asserts a proposition that is trivially true, and therefore uninformative, the audience will assume that the speaker intends to communicate a more substantial proposition that is related to the asserted proposition in subject matter and will look around for salient propositions that have these properties. (Emery and Hill 2017, 139)

For an important reason, their suggestion cannot be an explanation for an assertion of (5) made by a philosophically unsophisticated speaker. This is because the speaker and his or her audience do not consider (5) to be vacuously true. As Emery and Hill admit, they do not attempt to explain this mechanism; however, they do believe that it is a 'pragmatic mechanism of some sort' $(2017,139 \mathrm{n} 1)$.

The above is supposed to show how one can address the problem of counterpossibles without changing the orthodox account of counterfactuals. If Emery and Hill's approach 
is plausible, then an unorthodox analysis may be considered to be superfluous. After all, as the authors have argued, one does not have to change the semantic analysis or introduce impossible worlds in order to address intuitions that underpin the problem of counterpossibles. These intuitions may be explained away by indicating that the problem of counterpossibles is pragmatic in nature.

\section{Double-edged sword}

The described view might be challenged when confronted with the tu quoque fallacy. ${ }^{7}$ Emery and Hill use a line of argumentation which supports the orthodox view against the charge of its insufficient explanation of data. This means that it purports to reveal that one can explain away pre-theoretical intuitions about counterpossibles with the view that while some counterfactuals with merely possible antecedents are false, each and every counterfactual with an impossible antecedent is true. However, if the assertion of (1) does not affect the truth value of (2), one may adopt the very same strategy to claim that no counterfactual is false. As a consequence, one could use the above-mentioned arguments to claim that every counterfactual is vacuously true. This is because in the case of counterfactuals with merely possible antecedents, we can indicate indirect propositions that are expressed by their assertion. Consider counterfactuals such as the following:

(9) If Tom studied for two more hours, he would get a better grade.

(10) If Tom studied for two more hours, he would not get a better grade.

In these cases, one can also indicate a true proposition that may be indirectly expressed by the assertion of (9): namely (9*) 'Tom hasn't been studying enough.' However, based on the arguments of Emery and Hill, this does not have to entail the non-vacuous truth of (9) and non-vacuous falseness of (10). If one focuses on the notion of the assertion of counterfactuals instead of the notion of their truth value, one may claim that both are true (at the same time), but that for pragmatic reasons, one asserts (9). As such, Emery and Hill's approach need not be limited merely to counterfactuals with impossible antecedents, but may apply to any counterfactuals whatsoever.

Based on the above, one could defend a simple account for the truth value of counterfactuals, according to which every conditional with a merely possible or impossible antecedent is vacuously true. What differs in particular examples is that some of them indirectly express interesting true propositions while others do not. As such, every conditional (whether indicative or subjunctive) may be considered to be a material conditional 'in disguise.' Consequently, every expression of the form 'A $>\mathrm{C}$ ' would be true if the antecedent were false or the consequent were true.

While many believe that inductive conditionals may be analyzed in terms of material conditionals, for an important reason, subjunctive conditionals (i.e., counterfactuals)

\footnotetext{
$\overline{7}$ Since the case of philosophically sophisticated people has been described by Emery and Hill in more detail, I will ignore the explanation of the assertion of (5) by a philosophically unsophisticated speaker. I do believe, however, that if there is, as mentioned, an analogy between those two cases, our analysis should apply to both of them.
} 
require a different approach (Lewis 1973; Jackson 1979). Among other reasons, this is so because we do not assert counterfactuals merely because they are true, but also because a counterfactual with the same merely possible antecedent and opposite consequent is considered false. By defending orthodoxy, Emery and Hill seem to share this view. Acceptance of their pragmatic approach, however, undermines the importance of the assumption of the non-vacuous truth of counterfactuals.

The unorthodox motivation for ascribing a non-vacuous truth value to counterpossibles is very similar. This is the observation that the reason we do not want to assert (2), (4), (6), (8) is not merely that they indirectly express false propositions, but because assertion of (1), (3), (5), and (7) excludes assertion of (2), (4), (6), and (8) - just as assertions of (9) exclude assertions of (10). This similarity may be helpful in indicating the reason why a pragmatic approach is insufficient when it comes to analyses of counterpossibles.

\section{Counterfactuals and Counterpossibles}

Considering Emery and Hill's approach, the disagreement between orthodoxy and unorthodoxy might be grounded in the motivations for assertion of counterpossibles, such as (1) and a lack of assertion of (2). In the case of orthodoxy, this is grounded in the fact that (1) indirectly expresses an interesting and true proposition, while (2) indirectly expresses a false proposition. However, this - Emery and Hill claim - does not affect the truth value of (1) and (2). Both of them are vacuously true. Advocates of unorthodoxy, on the other hand, hold that the assertion of (1) excludes assertion of (2), because if (1) is true, (2) is false and, as such, should not be asserted.

As we have seen, Emery and Hill's approach also works well for counterfactuals such as (9) and (10). In those cases one may want to argue that we assert (9) not because of its non-vacuous truth, but merely because it indirectly expresses a true proposition $\left(9^{*}\right)$. Consequently, we do not assert (10) not because it is false in the face of the assertion of (9), but because any interesting proposition that may be indirectly expressed by its assertion is false. This, however, does not have to be the case. Consider, for example, the aforementioned procedure of identifying an indirect proposition. According to Emery and Hill's approach, if a speaker asserts a vacuously true conditional, the audience assumes that she meant to express an interesting and true proposition. By the principle of charity, the audience assumes that there is such a proposition and aims to identify it. It seems that this also works well for assertions of (10). The following might be considered an indirect expression of (10*): 'Tom needs to sleep well the night before an exam."

The above shows that — by virtue of the pragmatic approach — assertion of (9) does not exclude assertion of (10). Both are vacuously true, both indirectly express true and interesting propositions, and both have the same (or at least similar) subject matters. It is, however, very unlikely that one would simultaneously assert both of them. Moreover, it seems that every substantive disagreement on hypothetical states of affairs and

\footnotetext{
${ }^{8}$ An assertion of (10) does not seem to be the simplest way to communicate $(10 *)$; however, the same is true of other examples of counterfactuals and the indirect propositions they might express.
} 
their consequences is grounded in the fact that ' $\mathrm{A}>\mathrm{C}$ ' is inconsistent with ' $\mathrm{A}>\sim \mathrm{C}$ '. The lack of simultaneous assertion of such counterfactuals should be explained.

One could argue that the propositions indirectly expressed by (9) and (10) contradict each other and, because of this, we assert only one of these. Nevertheless, there is no contradiction between $\left(9^{*}\right)$ and $\left(10^{*}\right)$. Both might be directly expressed without confusing the audience. The other reason might be the assumption that if, in a given context, assertion of (9) has been used to express $\left(9^{*}\right)$, then (10) (by virtue of being a negation of (9)) has been used to express the negation of (9*); e.g., (10**) 'Tom's problem is not that he hasn't studied enough.' While this seems to be a plausible assumption, it is difficult to agree on it without the belief that (9) and (10) are mutually inconsistent. After all, if two sentences in the same context express inconsistent propositions, there is no reason to take these sentences to be consistent with each other. In this sense, lack of assertion of (10) is grounded in the fact that by virtue of assertion of (9), (10) is false. This also seems to be a justification for the substantiveness of debates about hypothetical states of affairs and their consequences.

In light of the analogy between pragmatic approaches toward truth values of counterfactuals and counterpossibles, it's no wonder that in the latter case we find a very similar situation. There is a context in which not (8) but (7) might be asserted; e.g., to express $\left(8^{*}\right)$ 'No man is a married bachelor.' As in the cases of $\left(9^{*}\right)$ and $\left(10^{*}\right)$, there is no contradiction between $\left(7^{*}\right)$ and $\left(8^{*}\right)$. Nevertheless, it is very unlikely that one would in the same context assert both (8) and (7). This might be explained by the assumption that if a counterpossible (or a counterfactual in general) ' $\mathrm{A}>\mathrm{C}$ ' is true, the opposite ' $\mathrm{A}>\sim \mathrm{C}$ ' is false.

\section{Summary}

The close bond between counterfactuals with possible and impossible antecedents allows us to claim that if a pragmatic approach justifies belief in the vacuous truth of counterpossibles, it is difficult to find a reason for which the very same approach could not be applied to counterfactuals in general. This, however, would result in the view that every counterfactual is vacuously true, which seems to be an unwelcome consequence of Emery and Hill's approach for two reasons. The main reason is that this fails to explain the fact that we do not assert (in the same context) counterfactuals of the same antecedent and opposite consequences. The second is that critiques of unorthodoxy are often committed to the standard possible worlds approach toward counterfactuals, according to which some of them are true and others are false. As I have argued, the pragmatic strategy might be easily extended to cases of counterfactuals with merely possible antecedents. As a result, the pragmatic approach equally undermines the orthodox and the unorthodox views on counterpossibles and counterfactuals in general. This makes it hard to believe in the vacuous truth of the former and not believe in the vacuous truth of the latter.

While Emery and Hill manage to stress the important pragmatic aspect of counterfactuals, their proposal in its current form requires completion. This should be done either (i) by arguing that all counterfactuals are vacuously true, or (ii) by giving reasons for which a pragmatic approach should be limited merely to counterfactuals with impossible antecedents. Otherwise, the theoretical costs of this approach-compared with its advantages over the unorthodox view-make it difficult to accept. 
Open Access This article is distributed under the terms of the Creative Commons Attribution 4.0 International License (http://creativecommons.org/licenses/by/4.0/), which permits unrestricted use, distribution, and reproduction in any medium, provided you give appropriate credit to the original author(s) and the source, provide a link to the Creative Commons license, and indicate if changes were made.

\section{References}

Berto, F. 2013. Impossible Worlds. In E. N. Zalta (Ed.), The Stanford Encyclopedia of Philosophy. http://plato. stanford.edu/entries/impossibleworlds Accessed 10 Oct 2016.

Brogaard, B., \& Salerno, J. (2013). Remarks on Counterpossibles. Synthese, 190, 639-660.

Carston, R. (2017). Pragmatics and Semantics. In Y. Huang (Ed.), The Oxford Handbook of Pragmatics (pp. 453-472). Oxford: Oxford University Press.

Emery, N., \& Hill, C. (2017). Impossible Worlds and Metaphysical Explanation: Comments on Kment's Modality and Explanatory Reasoning. Analysis, 1(1, January 2017), 134-148.

Grice, H. P. (1975). Logic and conversation. In P. Cole \& J. Morgan (Eds.), Syntax and Semantics, 3: Speach Acts (pp. 41-58). New York: Academic Press.

Jackson, F. (1979). On Assertion and Indicative Conditionals. Philosophical Review, 88, 565-589.

Kment, B. (2015). Modality and Explanatory Reasoning. Oxford: Oxford University Press.

Kripke, S. (1972). Naming and Necessity. Oxford: Basil Blackwell Pub.

Lewis, D. (1973). Counterfactuals. Oxford: Blackwell.

Nolan, D. (1997). Impossible Worlds: Modest Approach. Notre Dame Journal of Formal Logic, 38(4), 535572.

Priest, G. (2009). Conditionals: a Debate with Jackson. In I. Ravenscroft (Ed.), Minds, Worlds and Conditionals: Themes from the Philosophy of Frank Jackson (pp. 311-335). Oxford: Oxford University Press.

Putnam, H. (1973). Meaning and Reference. Journal of Philosophy, 70, 699-711.

Quine, W. V. (1960). Word and Object. Cambridge: M.I.T. Press.

Sendłak, M. (2017). Counterpossibles, Impossible Worlds and the Notion of Similarity. In R. Urbaniak \& G. Payette (Eds.), Applications of Formal Philosophy: The Road Less Travelled (pp. 221-241). Dordrecht: Springer.

Sendłak, M. Forthcoming. On the Motivation for the Dispute of Counterpossibles. Studia Semiotyczne English Supplement.

Stalnaker, R. (1968). A Theory of Conditionals. In N. Rescher (Ed.), Studies in Logical Theory (pp. 98-112). Oxford: Blackwell.

Szabó, Z. G. (2008). The Distinction between Semantics and Pragmatics. In E. Lepore \& B. C. Smith (Eds.), The Oxford Handbook of Philosophy of Language (pp. 361-390). Oxford: Oxford University Press.

Williamson, T. 2016. Counterpossibles. Topoi [online first].

Yagisawa, T. (1988). Beyond Possible Worlds. Philosophical Studies, 53, 175-204. 